\title{
Erratum to: Theory of Cryptography
}

\author{
Daniele Micciancio \\ University of California, San Diego, Computer Science \& Engineering Department, \\ 9500 Gilman Drive, La Jolla, CA 92093-5004, USA \\ daniele@cs.ucsd.edu
}

\section{Erratum to: \\ D. Micciancio (Ed.) \\ Theory of Cryptography \\ DOI: $10.1007 / 978-3-642-11799-2$}

The book was inadvertently published with an incorrect name of the copyright holder. The name of the copyright holder for this book is: (c) Springer-Verlag Berlin Heidelberg. The book has been updated with the changes.

The updated original online version for this book can be found at DOI: $10.1007 / 978-3-642-11799-2$

D. Micciancio (Ed.): TCC 2010, LNCS 5978, p. E1, 2010.

(C) Springer-Verlag Berlin Heidelberg 2017 